\title{
COERÊNCIA E VERACIDADE NA COMUNICAÇÃO: INDICIALIDADE INTRACOMUNICACIONAL E EXTRACOMUNICACIONAL'
}

\author{
COHERENCE AND TRUTHFULNESS IN COMMUNICATION: \\ INTRACOMMUNICATIONAL AND EXTRACOMMUNICATIONAL INDEXICALITY \\ COHERENCIA Y VERACIDAD IN LA COMUNICACIÓN: INDICIALIDAD \\ INTRACOMUNICACIONAL Y EXTRACOMUNICACIONAL
}

Lars Elleström²

Tradução - Marcelo Pires de Oliveira

RESUMO: O objetivo deste artigo é construir um modelo para demonstrar como a comunicação humana, envolvendo todos os tipos de mídia, pode não apenas corresponder, mas também nos colocar em contato com a nossa percepção do mundo que nos rodeia. De que maneiras a verdade é realmente estabelecida pela comunicação? Para responder a isso, emprega-se a noção de índices: sinais baseados em contiguidade. No entanto, uma investigação dos índices na sua dimensão externa - criando a veracidade na comunicação - também requer uma compreensão da sua dimensão interna: criar a coerência. Para investigar essas duas funções, alguns conceitos e várias categorizações elementares são

\footnotetext{
Este artigo, originalmente, foi publicado em inglês. O autor fez uma atualização para tradução e publicação em português, nesta revista, a convite do PPGCom da Famecos/PUCRS.

2 Ph.D Comparative Literature. Professor de Literatura Comparada na Universidade de Linnaeus, na Suécia. Principais obras: Divine Madness: On Interpreting Literature, Music, and the Visual Arts Ironically (Bucknell University Press, 2002), Media Borders, Multimodality and Intermediality (Palgrave Macmillan, 2010) and Media Transformation: The Transfer of Media Characteristics Among Media (Palgrave Macmillan, 2014). ORCID: 0000-0002-8664-1970 - E-mail: ars.ellestrom@Inu.se

3 Professor Adjunto da Universidade Estadual de Santa Cruz, Bahia. Doutor em Multimeios pela Universidade Estadual de Campinas. Pós-doutorando do Programa de Pós-graduação da Escola de Comunicação, Artes e Design, da Pontifícia Universidade Católica do Rio Grande do Sul. - ORCID: 0000-0002-1923-8276 E-mail: mpoliveira@uesc.br
} 
propostas: argumenta-se que existem vários tipos de contiguidade e muitas variedades de objetos indiciais, o que invalida a distinção grosseira entre ficção e não ficção.

Palavras-chave: Comunicação. Mídia. Ficcionalidade.

ABSTRACT: The aim of this article is to construct a model that demonstrates how human communication, involving all kinds of media, may not only correspond to but also put us in contact with what we perceive to be the surrounding world. In which ways is truthfulness actually established by communication? To answer this, the notion of indices is employed: signs based on contiguity. However, an investigation of indices' outward direction - creating truthfulness in communication - also requires an understanding of their inward direction: establishing coherence. To investigate these two functions, further concepts and various elementary categorizations are proposed: it is argued that there are several types of contiguity and many varieties of indexical objects, which invalidates the coarse fiction-nonfiction distinction.

Keywords: Communication. Media. Fictionality.

RESUMEN: El propósito de este artículo es construir un modelo para demostrar cómo la comunicación humana, que involucra a todo tipo de medios, no solo puede coincidir sino también ponernos en contacto con nuestra percepción del mundo que nos rodea. ¿De qué maneras se establece realmente la verdad mediante la comunicación? Para responder a esto, se emplea la noción de índices: señales basadas en contigüidad. Sin embargo, una investigación de los índices en su dimensión externa, crear verdad en la comunicación, también requiere una comprensión de su dimensión interna: crear coherencia. Para investigar estas dos funciones, se proponen algunos conceptos y varias categorizaciones elementales: se argumenta que existen varios tipos de contigüidad y muchas variedades de objetos indicativos, lo que invalida la gran distinción entre ficción y no ficción.

Palabra clave: Comunicación. Medios. Ficcionalidad.

\section{Introdução}

A veracidade na comunicação deve ser investigada da forma mais completa possível, pois envolve exatidão, confiabilidade e valor. Construir conexões reais com o mundo é fundamental para muitas áreas da comunicação, e os equívocos a respeito da (não) veracidade comunicativa podem ter graves implicações para os indivíduos e para a sociedade em geral. 
Como a veracidade, em todos os tipos de comunicação humana, pode ser conceituada para que possa ser metodicamente investigada? Esta é a questão epistemológica que pretende desvendar este artigo. As pesquisas que existem examinam, principalmente, como certas proposições verbais correspondem ou não a circunstâncias já conhecidas. Esses tratados filosóficos investigam principalmente um uso particular de palavras que são entendidas como símbolos: sinais habituais. Embora interessantes, tais investigações dizem pouco sobre como a veracidade é realmente entendida pela comunicação. Isso requer um foco em outros tipos de signos, isto é, índices, que se conectam a objetos não com base em hábitos ou convenções, mas em relações de contiguidade ou conexões reais.

Além disso, requer atenção a todos os tipos de mídia comunicativa, não apenas aqueles que envolvem a linguagem. Produtos de mídia são entidades materiais intermediárias (corporais ou não corporais) com capacidades semióticas que possibilitam a transferência do valor cognitivo entre as mentes humanas por meio da representação; os produtos de mídia, portanto, agem como coleções de signos materiais que permitem o compartilhamento de objetos mentais (ELLESTRÖM, 2018). Note que a distinção material-mental é usada não apenas para destacar uma diferença entre os dois reinos, mas também para demonstrar a sua forte interdependência.

O objetivo deste artigo é construir um modelo de como a comunicação humana pode nos colocar em contato com o que percebemos como sendo o mundo que nos rodeia por meio dos índices: uma estrutura conceitual para analisar a veracidade nos complexos processos de comunicação que muitas vezes é multimodal. Ele deve ser válido para todos os tipos de mídia, incluindo aqueles que são profundamente diferentes: notícias, fotografias, testemunhos, romances, músicas, chats, carícias e diagramas científicos.

Como será demonstrado, no entanto, tal estrutura requer uma compreensão não apenas da dimensão externa dos índices - gerando a veracidade na comunicação - mas também de sua dimensão interior: formando a coerência. Essas duas facetas serão, portanto, investigadas como as principais funções dos índices na comunicação humana.

Consequentemente, o objetivo é precisar alguns princípios teóricos básicos sobre como a coerência e, especialmente, como a veracidade são alcançadas na comunicação. Proporei uma série de distinções das quais o mais essencial é aquele entre dois domínios diferentes na mente do perceptor de produtos de mídia: o intracomunicacional, criado no ato de comunicação, e o extracomunicacional, existente antes e fora do ato de comunicação. As duas funções básicas dos índices na comunicação podem, portanto, ser identificadas como indicialidade intracomunicacional (coerência 
interna) e indicialidade extracomunicacional (veracidade externa). Para investigar essas funções adequadamente, apresentarei novos conceitos e também proponho várias categorizações elementares em algumas áreas vitais, mas subpesquisadas; existem vários tipos de contiguidade e numerosas variedades de objetos indiciais.

Minha abordagem será semiótica, usando algumas das concepções fundamentais de Charles Sanders Peirce e a sua noção de índice - que tem sido surpreendentemente pouco usada nesse tipo de pesquisa - como ponto de partida. Tentarei compreender todo o campo da comunicação humana, indo além da análise da veracidade em frases escritas isoladas. A tradição da pesquisa filosófica com a lógica modal é, portanto, apenas marginalmente relevante, assim como muitas das próprias ideias de verdade de Peirce nas proposições (discutido em BURKE, 1991; HOWAT, 2015), embora discuta o papel dos índices nas proposições verbais (HOOKWAY, 2000, p. 82-134) e está inclinado a pensar em raciocínio e proposições em termos que são mais amplos do que apenas a linguagem (STJERNFELT, 2014). Exceto por sua noção de índice, essencial para entender como a comunicação se conecta às nossas experiências do mundo ao redor (BERGMAN, 2009), o artigo não se baseia nas ideias filosóficas gerais de Peirce sobre realidade e verdade (MCCARTHY, 1984; NESHER, 1997).

Meu próximo passo será, portanto, um olhar mais aprofundado da noção de índice de Peirce e mapear brevemente a área de objetos indiciais. Em seguida, apresentarei minha distinção entre os domínios intracomunicacionais e extracomunicacionais, incluindo discussões sobre a natureza dos objetos a eles associados, que serão seguidos por uma descrição mais refinada das esferas dentro dos dois domínios. Depois disso, vou sugerir um catálogo fundamental de diferentes tipos de contiguidade, permitindo-nos discernir várias bases de coerência interna e veracidade externa. As seções subsequentes serão dedicadas ao mapeamento de variedades de coerência interna (mais incompletas) e veracidade externa (incluindo uma lista de tipos de objetos indiciais extracomunicacionais). Além disso, a noção de mentes comunicativas será examinada à luz de um quadro conceitual. Finalmente, criticarei brevemente as noções de ficcionalidade e ficção em favor de uma concepção mais refinada de indicialidade extracomunicacional ou veracidade externa.

\section{Îndices como conexões reais}

Para desenvolver o modelo, algumas noções básicas semióticas derivadas de Peirce devem ser esclarecidas. Mais fundamentalmente, ele distingue entre três componentes do signo: “Um signo, ou representamen, é algo que significa algo para 
alguém em algum aspecto ou capacidade". Em outras palavras: o representamen representa um objeto em alguns aspectos e assim, "Cria na mente dessa pessoa" um interpretante (PEIRCE, 1897, p. 135). Isso implica que os signos não são itens estáticos, mas sim funções dinâmicas constituídas por constituintes inteiramente relacionais (existentes apenas em interação entre si) e mentalmente motivados. Observe que o termo objeto se refere a tal constituinte de sinal relacional ao longo do artigo.

A maneira mais produtiva de Peirce de distinguir entre diferentes tipos de signos é discernir a relação entre representamen e objeto, isto é, as entidades representativas e representadas. Como esses componentes não estão arbitrariamente conectados (o que levaria ao caos cognitivo), deve haver algum tipo de motivação para que a conexão aconteça na mente. Peirce, às vezes, chama essa motivação de base do representamen e difere entre três tipos de signos caracterizados por seus respectivos fundamentos: os ícones são baseados na similaridade, índices na contiguidade (1901, p. 172), e símbolos nos hábitos (essa tricotomia é elaborada de várias maneiras; ver, por exemplo, 1906). Como ícones, índices e símbolos têm bases diferentes, mas compatíveis (as coisas podem ser similares e contíguas ao mesmo tempo, por exemplo), elas dificilmente aparecem isoladamente, mas tendem a cooperar de várias maneiras.

O índice é a espinha dorsal da semiótica na minha opinião sobre coerência e veracidade na comunicação. Como é frequentemente o caso nos escritos de Peirce, essa noção está permeada de alguma flexibilidade. Como regra, ele enfatiza uma relação física de causa e efeito, ou seja, uma "conexão física direta", entre representamen e objeto (PEIRCE, 1885, p. 196). Peirce argumenta, assim, que as fotografias, que são "em certos aspectos exatamente como os objetos que representam", não são apenas ícones, mas também índices, pois são "produzidas sob tais circunstâncias que são fisicamente forçadas a corresponder ponto por ponto à natureza" (1895, p. 159). Da mesma forma, os sintomas das doenças são "sinais que se tornam tais em virtude de estarem realmente conectados com seus objetos" (1902, p. 92).

Embora Peirce enfatize repetidamente que o fundamento de um índice é real, fica claro que a noção de indicialidade vai além do real, entendido apenas em termos físicos. Ele também destaca conexões não físicas e, às vezes, ele afirma claramente que os índices não "têm referência exclusiva a objetos de experiência" (PEIRCE, 1901, p. 171) e que "não faz diferença se a conexão [entre representamen e objeto] é natural, ou artificial, ou meramente mental" (sem data). Deve-se notar, portanto, que há alguma tensão nos escritos de Peirce entre a sua insistência de que a indicialidade como tal é baseada em conexões físicas palpáveis e a sua noção mais ampla de indicialidade baseada também na 
contiguidade mental (essa tensão é criticada por Goudge 1965 e defendida por Atkin 2005). A solução é adotar a noção mais aplicável para uma ampla análise de comunicação: índices baseados em conexões reais em um sentido amplo, incluindo contiguidade material e mental (ELLESTRÖM, 2014, p. 102-105).

\section{Objetos indiciais}

Isso leva à pergunta: qual é a natureza dos objetos indiciais? No núcleo da semiose, representamens e os objetos, assim como os interpretantes, são mentais. No entanto, o representamen pode ter uma faceta material externa na medida em que é produzido pela percepção da materialidade; da mesma forma, os objetos podem ter uma faceta material externa na medida em que alcançam o material por meio da lembrança da antiga percepção sensorial da materialidade (ELLESTRÖM, 2014).

A semiose na comunicação ou, mais precisamente, a semiose que é imediatamente acionada pelos produtos da mídia, é sempre construída sobre o representamen material. Além disso, a semiose na comunicação, como toda semiose, consiste em grande parte de cadeias de signos mentais, nas quais os interpretantes se transformam em novos quadros mentais, criando novos interpretantes e assim por diante. Em um enunciado como "estou em casa", o som material da voz tende a formar símbolos cujos interpretantes formam índices mentais referentes a uma pessoa específica em um lugar específico.

Em contraste, os objetos dos signos comunicativos podem ser tanto mentais quanto materiais. Como a contiguidade pode ser tanto material como mental, isso inclui objetos indiciais. Uma lista que abranja todos os tipos de objetos indiciais equivaleria a tudo o que é conhecido, então eu irei aqui apenas dar alguns exemplos gerais para demonstrar a grande variedade de fenômenos que a comunicação humana pode representar indicialmente. Uma categorização grosseira pode começar com objetos materiais, como coisas: corpos, animais e pessoas; qualidades físicas, propriedades e condições; estados de coisas; ações, movimentos e eventos; certos lugares em determinados momentos etc. Em contraste, há objetos mentais como percepções, experiências, emoções, processos psicológicos, ideias, convicções, ideologias, conceitos, conhecimentos, volições, intenções etc. Como o reino mental está muito interligado e formado pela experiência do reino material, muitos objetos transgridem a simples divisão material-mental. Esses incluem, por exemplo, relações espaço-temporais derivadas da experiência de ser um corpo interagindo com um mundo circundante: distâncias, posições, inter-relações, proporções, equilíbrio, estruturas e contrastes. 
Estes e muitos outros objetos podem, portanto, ser representados por meio de ícones, índices, símbolos e, mais comumente, pela combinação deles. Não há nada de extraordinário em objetos indiciais, exceto que eles são representados no campo da contiguidade; isto é, das conexões reais. A seguir, as diferentes funções dessas conexões reais e a natureza das várias esferas mentais em que os objetos indiciais estão localizados na comunicação serão investigadas.

\section{Domínios e objetos intracomunicacionais e extracomunicacionais}

Notamos que os representamens que iniciam a semiose na comunicação vêm da percepção sensorial dos produtos de mídia. Percebemos configurações de som, visão, tato e assim por diante que são criadas ou trazidas por alguém e entendidas como significando algo. Mas de onde vêm os objetos? Eles claramente não emergem do nada, mas são desenvolvidas de percepções, sensações e noções anteriores que são armazenadas, seja na memória de longo prazo ou de curto prazo, e que também podem recair sobre a comunicação em progresso. "Mais cedo" pode, portanto, ser um século atrás ou uma fração de segundos atrás.

Em termos semióticos, as entidades mentais armazenadas podem ser percepções diretas de fora da comunicação, interpretantes da semiose fora da comunicação, interpretantes da semiose na comunicação anterior ou interpretantes da semiose nas interações comunicativas. Isto é para dizer que objetos de semiose sempre exigem "experiência colateral" (PEIRCE, 1909, p. 135-136; BERGMAN, 2009) que pode derivar tanto de dentro como de fora da comunicação em progresso. Em outras palavras: a experiência colateral pode ser formada por semiose dentro do quadro espaço-temporal do ato comunicativo, e se origina de outros envolvimentos anteriores com o mundo, incluindo a comunicação anterior, bem como a experiência direta da existência circundante.

Em consonância com essa dupla origem da experiência colateral, distingui duas áreas completamente entrelaçadas, mas, mesmo assim, dissimilares na mente do perceptor de produtos de mídia: os domínios intracomunicacional e extracomunicacional, enfatizando uma diferença entre a formação de valor cognitivo na comunicação em curso e aquilo que o precede e o rodeia ${ }^{4}$. Eu também acho apropriado fazer uma distinção correspondente entre os objetos intracomunicacionais e extracomunicacionais, ambos formados pela experiência colateral de seus respectivos domínios.

4 Cf. distinções relacionadas, mas divergentes, na psicologia cognitiva, propostas por Brewer (1987, p. 187). 
Consequentemente, existem objetos indiciais intracomunicacionais e extracomunicacionais. Como os índices são baseados em conexões reais, eles são igualmente importantes para os dois domínios. Por um lado, ligam as entidades no domínio intracomunicacional entre si e, assim, criam a coerência. Índices intracomunicacionais são a cola da semiose, impedindo que os interpretantes separados criados na comunicação se desintegrem. Por outro lado, eles ligam entidades no domínio intracomunicacional a entidades no domínio extracomunicacional e, assim, determinam a veracidade de vários tipos e graus. Índices extracomunicacionais são a âncora da semiose, impedindo que os interpretantes da comunicação se afastem do domínio extracomunicacional.

Isso quer dizer que as junções indiferenciadas de representamens e objetos resultam em interpretantes que nos convencem de que há alguma coerência no que está sendo comunicado e que o seu conteúdo está de alguma maneira ligado a algo externo ao quadro espaço-temporal do ato comunicativo.

De uma perspectiva temporal, o domínio extracomunicacional é claramente anterior a cada novo domínio intracomunicacional criado. É por isso que vou delinear superficialmente o domínio extracomunicacional antes de explorar o domínio intracomunicacional. No entanto, eventualmente se tornará claro que o modelo esboçado aqui tem o seu centro no domínio intracomunicacional; e que minhas construções conceituais estão moldadas do ponto de vista desse domínio. O discernimento de algo extracomunicacional é obviamente uma consequência de se concentrar no que é intracomunicacional.

\section{Domínio extracomunicacional}

O domínio extracomunicacional deve, portanto, ser entendido como o pano de fundo na mente do perceptor dos produtos de mídia. Compreende tudo aquilo que o receptor já conhece e domina. Como é um domínio mental, não consiste no mundo como tal, mas sim no que se conhece por meio da percepção e semiose. Isso quer dizer que as experiências armazenadas não consistem apenas de percepções como tais, mas também de percepções que foram contempladas e processadas pela mente por meio de semiose.

O domínio extracomunicacional inclui experiências tanto do que se presume serem estados de coisas mais objetivos (cães, universidades, música e relações estatísticas) quanto do que se supõe ser estados de coisas mais subjetivos (estados de espírito relacionados a experiências individuais). É assim, na verdade, formada na mente de alguém, não apenas por meio da semiose e da percepção externa imediata, 
mas também pela intercepção, propriocepção e introspecção mental. A distinção extracomunicacional - intracomunicacional é, portanto, muito diferente do exterior - interior para a mente, mundo - indivíduo, material - mental e objetivo - subjetivo.

É importante notar que partes vitais do domínio extracomunicacional são constituídas pela percepção e interpretação de produtos de mídia. A comunicação anterior é, portanto, parte do que precede e envolve a comunicação em curso. Juntas, experiências prévias não comunicativas e comunicativas formam "um horizonte de possibilidades", para tomar emprestada uma expressão de Marie-Laure Ryan (1984, p. 127); o domínio extracomunicacional é o reservatório do qual as entidades são selecionadas para formar novas constelações de objetos no domínio intracomunicacional.

\section{Domínio intracomunicacional}

Em contraste com o domínio extracomunicacional, o domínio intracomunicacional é a área de primeiro plano na mente do receptor dos produtos de mídia. Ela é formada pela percepção e interpretação dos produtos de mídia presentes no ato das interações comunicativas. Baseia-se tanto em objetos extracomunicacionais - emanando do domínio extracomunicacional - quanto em objetos intracomunicacionais - que surgem no domínio intracomunicacional - que, juntos, resultam em interpretantes que constituem o valor cognitivo na mente do receptor. No entanto, o domínio intracomunicacional está amplamente mapeado no domínio extracomunicacional. Revisitando o "Princípio da partida mínima”(desvio mínimo) de Ryan (1980, p. 406), eu argumento que se constrói o domínio intracomunicacional como sendo o mais próximo possível do domínio extracomunicacional e que permite desvios apenas quando não pode ser evitado. Como o domínio intracomunicacional é formado pela semiose comunicativa, pode-se dizer que existe em uma esfera virtual. O virtual não deve ser entendido em oposição ao real, mas como algo com potencial. Defino, portanto, o virtual como uma esfera mental, criada pela semiose comunicativa, que tem o potencial de ter conexões reais com o domínio extracomunicacional. Uma esfera virtual pode, portanto, representar objetos extracomunicacionais indicialmente e ser externamente verdadeira.

Uma esfera virtual pode consistir em qualquer coisa, desde um breve pensamento desencadeado por algumas palavras faladas, um gesto ou uma rápida olhada em um anúncio, até uma narrativa complexa ou uma teoria científica formada por horas assistindo televisão ou lendo livros. Dependendo do grau de atenção aos produtos de mídia, as bordas de uma esfera virtual não precisam necessariamente ser claramente definidas. Como a comunicação geralmente é 
tudo menos perfeita, uma esfera virtual pode ser extremamente incompleta ou até fragmentária. Também pode compreender o que se apreende como ideias conflitantes ou noções inconsistentes. Como as esferas virtuais resultam da comunicação, elas são, por definição, até certo ponto, compartilháveis entre as mentes.

A coexistência de objetos intracomunicacionais e extracomunicacionais resulta em uma possível visão dupla sobre as esferas virtuais: a partir de um ponto de vista, formam esferas autogovernadas com certo grau de autonomia; de outro ponto de vista, eles são sempre excessivamente dependentes do domínio extracomunicacional. O ponto crucial é que objetos intracomunicacionais não podem ser criados do nada "ex nihilo"; na verdade, eles são completamente derivados de objetos extracomunicacionais. Isto é porque nada pode realmente ser compreendido na comunicação sem o recurso de objetos extracomunicacionais. Mesmo as narrativas mais fantasiosas exigem objetos reconhecíveis para fazer sentido (BERGMAN, 2009, p. 261). Para ser mais preciso: os objetos intracomunicacionais são sempre partes, combinações ou junções de objetos extracomunicacionais; ou, para ser ainda mais exato: objetos intracomunicacionais são partes, combinações ou junções de interpretantes resultantes da representação de objetos extracomunicacionais.

É possível representar, digamos, grifos (que, pelo que sabemos, existem apenas em esferas virtuais) por causa do conhecimento de objetos materiais extracomunicacionais, como leões e águias, que podem ser facilmente combinados. Uma esfera virtual pode até incluir noções como um quadrado redondo, consistindo em dois objetos extracomunicacionais mutuamente exclusivos juntos formando um estranho objeto intracomunicacional. Personagens literárias, como Lily Briscoe, no romance de Virgínia Woolf, Ao Farol, são objetos intracomunicacionais compostos que consistem em material extracomunicacional e objetos mentais que derivam do mundo conhecido. Não se pode imaginar Lily Briscoe, a menos que se esteja bastante familiarizado com noções como andar, falar e comer; o que significa dirigir-se a pessoas de certas posições sociais; o que são mulheres e homens, adultos e crianças; o que significa amar e ficar entediado; e o que é criação artística. Além disso, objetos extracomunicacionais mais puramente mentais podem ser modificados ou unidos em novos objetos mentais intracomunicacionais. Objetos como emoções familiares podem ser combinados em novos objetos intracomunicacionais resumindo-se, digamos, em conflitos com misturas de emoções que são percebidas como únicas, embora já se conheçam os seus componentes.

Surge então a questão: se todos os objetos intracomunicacionais são, em última análise, derivados de objetos extracomunicacionais, como as esferas virtuais são frequentemente experimentadas como tendo um certo grau de autonomia? Isso 
ocorre porque eles, em parte ou no todo, podem ser percebidos como novos gestalts que interrompem a conexão com o domínio extracomunicacional. A razão para não serem reconhecidas é que elas não foram anteriormente conhecidas na constelação particular em que aparecem na esfera virtual. Várias dessas rupturas levam a uma maior autonomia do domínio intracomunicacional percebido. Embora os objetos intracomunicacionais sejam inteiramente dependentes de objetos extracomunicacionais, pode-se dizer que eles emergem dentro do domínio intracomunicacional.

A relação entre objetos extracomunicacionais e intracomunicacionais pode ser ainda mais complexa do que até agora indicado. Objetos intracomunicacionais que são percebidos como novos gestalts podem, por sua vez, fazer parte de gestalts mais abrangentes que são reconhecidos a partir do domínio extracomunicacional. Uma esfera virtual pode conter representações de objetos intracomunicacionais, como "trens vivos" formados por objetos extracomunicacionais familiares, como "máquinas feitas pelo homem para o transporte" e "a qualidade de ser animado e consciente", que juntos formam uma nova gestalt. Quando os "trens vivos" brigam ou se apaixonam um pelo outro, eles interagem de uma maneira que é reconhecida a partir do domínio extracomunicacional. A conclusão é que os objetos intracomunicacionais podem ser intercalados entre objetos extracomunicacionais de maneiras numerosas e complicadas.

\section{A esfera virtual, outras esferas virtuais, esfera real percebida}

Tendo descrito, com alguns detalhes, as inter-relações entre os domínios intracomunicacional e extracomunicacional, agora é hora de apresentar uma visão geral com a ajuda de um diagrama visual (Figura 1). O ponto principal é que, enquanto o domínio intracomunicacional consiste simplesmente em uma esfera virtual, o domínio extracomunicacional consiste em dois elementos bastante diferentes: de um lado, outras esferas virtuais; por outro lado, o que proponho chamar de esfera real percebida. Do ponto de vista de uma esfera virtual, existem assim, três esferas mais ou menos distintas: a esfera virtual em si, outras esferas virtuais e a esfera real percebida. 
Figura 1 - Esfera virtual, outras esferas virtuais, esfera real percebida

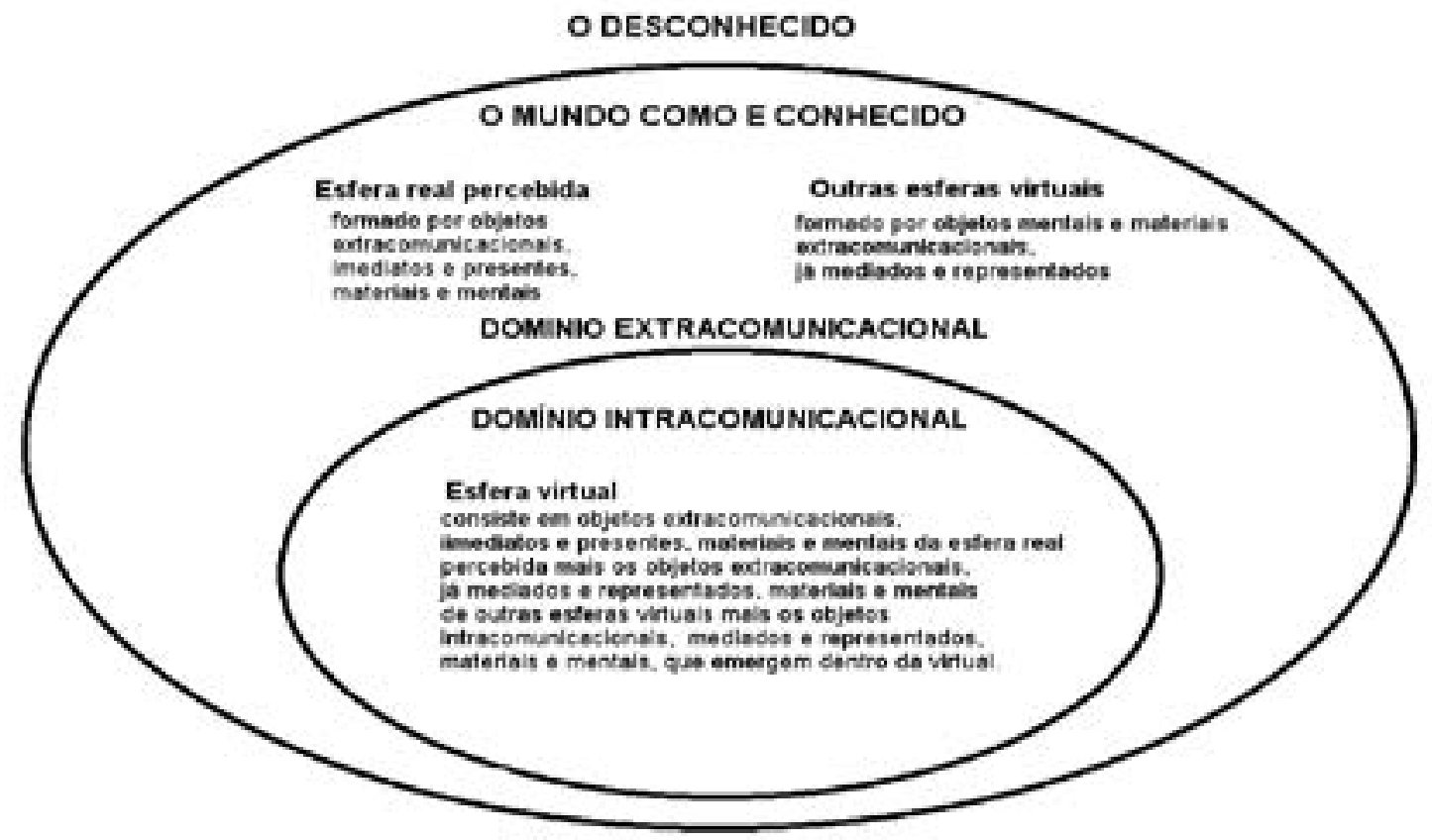

Fonte: elaborada pelo autor.

A esfera real percebida consiste em objetos extracomunicacionais, imediatos $e$ presentes, materiais e mentais, que estão além do domínio da comunicação com a qual a mente está familiarizada. O termo "percebido" deve ser entendido em um sentido amplo para incluir a exterocepção, a interocepção e a propriocepção, e também para ser associado à introspecção mental e à semiose com base na percepção da esfera real. "Imediato e presente" deve ser entendido em contraste com a comunicação: a esfera real percebida não consiste em representações mediadas formadas por produtos de mídia trazidos pela mente e suas extensões, mas está imediatamente presente para nós. Note que imediatamente presente não significa sem os mecanismos mentais mediadores que conectam a sensação à percepção ou às complicadas funções mediadoras que conectam a percepção ao mundo externo.

As outras esferas virtuais consistem em objetos mentais e materiais extracomunicacionais, já mediados e representados, com os quais a mente está familiarizada. Como as esferas virtuais são completamente semióticas, esses objetos são sempre feitos de interpretantes anteriores.

Assim, a esfera virtual consiste em objetos extracomunicacionais, imediatos e presentes, materiais e mentais da esfera real percebida, mais os objetos extracomunicacionais, já mediados e representados, materiais e mentais de outras 
esferas virtuais, mais os objetos intracomunicacionais, mediados e representados, materiais e mentais, que emergem dentro da virtual.

Como todas as representações esquemáticas, esse modelo destina-se a fornecer uma visão geral de uma realidade complexa. No entanto, não só aponta para áreas mentais que são fundamentalmente diferentes em certos aspectos, mas também revela suas complexas inter-relações. Deve-se então enfatizar que toda esfera virtual, do ponto de vista dessa esfera, é intracomunicacional e, portanto, composta de objetos que derivam de si mesma (na medida em que partes, combinações e junções de objetos extracomunicacionais podem ser entendidos como distintos), bem como de outras esferas virtuais e da esfera real percebida. Isto compreende uma mise-en-abyme ${ }^{5}$ : esferas virtuais intracomunicacionais são formadas por esferas reais, percebidas e por outras esferas virtuais extracomunicacionais que são, por sua vez, formadas por esferas reais, percebidas, e por outras esferas virtuais extracomunicacionais ad infinitum.

\section{Variedades de contiguidade}

Após essa visão geral das várias esferas, podemos examinar mais detalhadamente a indicialidade com maior ênfase em seu princípio central de contiguidade e como ela opera em relação à intracomunicacional e ao extracomunicacional. Seguindo Peirce, afirmei que os índices são sinais baseados em contiguidade ou conexões reais entre representamen e objeto. Embora essa seja uma noção semiótica fundamental, pouca pesquisa investigou o real significado de contiguidade. Quais são as conexões reais, em uma investigação mais profunda?

É geralmente aceito que as conexões reais consistem em contiguidade no espaço ou no tempo. Como devem ser entendidas em termos de materialidade e trabalho mental, as conexões reais podem acontecer por meio da percepção sensorial concreta do espaço físico e de sua transformação temporal, bem como por meio de sensações mais abstratas e conceituais de espaço e tempo. Essas duas facetas estão profundamente interligadas. De fato, pode-se dizer, indubitavelmente, que os índices evoluem durante a infância de uma compreensão dos objetos materiais (presentes) para também se conectar a objetos mentais (imaginados) (WEST, 2009; WEST, 2013); a partir de objetos imaginários, há apenas um pequeno passo para objetos que são ideias ou conceitos, e não entidades materiais. Dada essa escala material - mental deslizante, fica claro que

5 Mise-en-abyme - expressão francesa que significa narrativa em abismo (nota da tradução). 
conexões reais podem ser estabelecidas também entre entidades que diferem material e mentalmente. Além disso, é preciso lembrar que os índices, como outros signos, não são entidades objetivamente existentes, mas sim funções. Assim, a contiguidade, mesmo que seja entendida como conexão real no tempo e no espaço, pode ser mais ou menos direta, não ambígua e intersubjetiva ou indireta, ambígua e subjetiva. Além disso, experiências subjetivas são reais. No entanto, existem claramente variedades de contiguidade. Eu sugiro categorizar, por um lado, subclasses gerais que podem ser discernidas como tipos diferentes de relações entre entidades e, por outro lado, subclasses específicas que podem ser discernidas como tipos diferentes de canais relacionais entre entidades.

\section{Subclasses gerais de contiguidade}

Sob o título de subclasses gerais, temos contiguidade em um sentido mais fraco: copresença, que simplesmente inclui a proximidade, seja no sentido de ser adjacente ("pessoa em pé perto da porta") ou no sentido de fazer parte ("maçaneta da porta", "corpo humano incluindo mão"). Também temos contiguidade em um sentido mais forte: interação. A interação inclui proximidade e adicionalmente causalidade, entendida como unidirecional ("pessoa abrindo a porta") ou recíproca ("pessoa abrindo a porta que fecha e a atinge na cabeça").

A contiguidade como copresença, e especialmente a adjacência, tende a ser mais indireta, ambígua e subjetiva em comparação à contiguidade como interação. Como tudo pode ter algum tipo de copresença espaço-temporal com quase qualquer coisa, não há muito sentido em classificar essas conexões. As subclasses específicas listadas abaixo são, portanto, aplicáveis principalmente à contiguidade, entendida como interação. Esses tipos de conexões reais tendem a ser relativamente diretos, não ambíguos e intersubjetivos, embora não sejam, de modo algum, independentes da perspectiva humana sobre os eventos do mundo.

\section{Subclasses específicas de contiguidade}

A seguinte lista dos canais relacionais entre entidades não é de forma alguma completa e não há fronteiras claras entre as categorias; a classificação é meramente para fornecer uma visão ampla das conexões reais por meio de exemplos esclarecedores que vão da contiguidade material à mental. A contiguidade que não inclui atividades mentais no canal relacional entre entidades abrange a contiguidade mecânica (entre o dedo e a impressão digital; entre o arco sendo 
friccionado nas cordas e o som do violino); contiguidade eletromagnética (entre os fótons emitidos pela matéria e as fotografias digitais (GODOY, 2007); entre a digitação no teclado e o que é visto nas telas do computador); contiguidade química (entre os fótons emitidos pela matéria e as fotografias clássicas; entre o calor adicionado e a água fervente); e contiguidade orgânica (entre doença e sintomas observáveis; entre animal morto e fóssil).

Contiguidade que inclui atividades mentais corpóreas conscientes ou inconscientes no canal relacional entre entidades, por exemplo, combina a contiguidade mental e mecânica (entre a decisão de usar um lápis e um texto escrito; entre a raiva súbita e socar uma janela); e a combinação de contiguidade mental e orgânica (entre estado emocional e qualidade de voz, expressão facial e postura corporal; entre recusa a comer e sensação de fome).

Finalmente, há uma contiguidade que consiste meramente em atividades mentais conscientes ou inconscientes no canal relacional entre entidades (entre sensações e suposições; entre premissas e conclusões). A contiguidade, portanto, abrange o campo das conexões físicas concretas ao raciocínio abstrato que, em última análise, deriva de experiências de relações corporais.

Essas subclasses gerais e específicas de contiguidade iluminam como os objetos extracomunicacionais e intracomunicacionais se tornam parte das esferas virtuais. Deve-se lembrar, porém, que mesmo os índices que se baseiam em conexões reais mais fortes, isto é, interação, e que alcançam a esfera real percebida, representam apenas o mundo como é percebido. Não apenas contiguidades mentais, mas também mecânicas, eletromagnéticas, químicas e orgânicas são contiguidades presumidas formadas pela experiência colateral. No final, os domínios extracomunicacional e intracomunicacional são ambos mentais.

\section{Indicialidade intracomunicacional: coerência interna}

Depois de identificar uma grande variedade de contiguidades que formam os fundamentos para a indicialidade intracomunicacional e extracomunicacional, está na hora de examinar mais de perto as funções da indicialidade intracomunicacional e extracomunicacional: gerar coerência interna e veracidade externa, respectivamente.

A indicialidade intracomunicacional é a semiose que constrói vínculos dentro da esfera virtual, conectando os repositórios no terreno da contiguidade a objetos que são atraídos ou formados dentro da esfera virtual à medida que essa evolui. Como a semiose ocorre dentro de uma esfera virtual, as contiguidades também são virtuais. Além de ser capaz de manter o espaço e o tempo representados, uma 
esfera virtual é espaço-temporal no sentido de que é formada pela percepção e interpretação mais ou menos contínuas de produtos de mídia fisicamente mais ou menos demarcados. Mesmo se a percepção for interrompida, ou se partes dos produtos da mídia estiverem dispersos, a pessoa tem a capacidade mental de (re) conectar as partes de forma que elas representem uma esfera virtual consistente. Consequentemente, a sensação dos constituintes do produto da mídia, assim como o que eles representam, é que eles são minimamente copresentes. Os constituintes de uma esfera virtual são inicialmente, quando são primeiro percebidos, certamente adjacentes, e à medida que a percepção e a interpretação evoluem, eles são frequentemente entendidos como parte um do outro e em interação.

Como a mente se esforça para perceber gestalts, a pessoa está profundamente inclinada a usar essas conexões reais como base para os índices, o que leva a cadeias e teias de representações que criam coerência. Se a comunicação avança e faz sentido, seus constituintes são contíguos em um sentido mais forte e a indicialidade baseada na causalidade, e não simplesmente na adjacência, conduz a uma coerência ainda mais forte.

A coerência interna na comunicação pode, portanto, ser definida como conexões reais entre os representamens e objetos intracomunicacionais. Mas o que significa dizer que uma esfera virtual é coerente? Exemplos de junções indiciais intracomunicacionais são os seguintes: as pessoas e ações representadas parecem estar geralmente inter-relacionadas; eventos e humores parecem, de alguma forma, encadearem-se, em vez de ocorrer aleatoriamente; detalhes são apreendidos como partes discerníveis do todo mental ou material; estados psicológicos, ideias e conceitos são desenvolvidos inteligivelmente; propriedades físicas são associadas a objetos materiais de maneira consistente; ações físicas e psicológicas levam a reações que estão ligadas às ações; emoções são possíveis de entender no contexto de outras emoções e atividades; conceitos fazem sentido considerando o cenário; entidades e desenvolvimentos são percebidos como proporcionais, dado o quadro geral.

Junções indiciais como essas, baseadas em vários tipos de contiguidade, ocorrem em todos os tipos de produtos de mídia, sejam eles constituídos por uma quantidade limitada de materiais, modos espaço-temporais, sensoriais e semióticos (como imagens estáticas ou texto escrito) ou marcadamente multimodais (como filmes, que são tanto espacial e temporal, visual e auditivo e icônico e simbólico). Um papel importante da indicialidade intracomunicacional é, portanto, unir os diferentes modos de um produto de mídia por meio da representação intermodal, de modo que surja uma esfera virtual integrada, em vez de um conjunto de esferas mentais específicas e não relacionadas. 


\section{Indicialidade extracomunicacional: veracidade externa}

Em contraste, a indicialidade extracomunicacional é a semiose construindo ligações entre uma esfera virtual e o seu entorno, conectando os representamens no campo da contiguidade a objetos de fora da esfera virtual. Penso que isso é a veracidade externa na comunicação, que pode, portanto, ser definida como conexões reais entre os representamens intracomunicacionais e os objetos extracomunicacionais. A noção de veracidade que proponho é, portanto, entendida como um traço comunicativo concebido, que não deve ser confundido com a verdade, entendida como uma característica do mundo real, nunca totalmente acessível. No entanto, a verdade pode ser abordada por meio da comunicação verdadeira acumulada e da observação dos efeitos de outras ações com base na veracidade concebida.

Para que a comunicação pode ser verdadeira, mais precisamente? Penso que os objetos indiciais extracomunicacionais podem ser classificados de forma variada, cada categoria correspondendo a um certo tipo de veracidade. Vou dar aqui alguns exemplos proeminentes de tais objetos e veracidade. Não é uma classificação rígida, mas sim um inventário incompleto de tipos que às vezes se sobrepõem, algumas vezes se complementam e às vezes estão em conflito. Não aconselho de modo algum que sejam tratadas como categorias de compartimentalização; eles são grupos bastante flexíveis para investigações metódicas da veracidade na comunicação.

Após a divisão do domínio extracomunicacional em duas partes, podemos afirmar que uma esfera virtual pode ser verdadeira para objetos na esfera real percebida ou para objetos em outras esferas virtuais; às nossas noções do mundo circundante ou ao nosso conhecimento de uma comunicação anterior. Por sua vez, a comunicação anterior pode ser verdadeira para objetos na esfera real percebida ou para objetos em outras esferas virtuais. A noção de que pode haver representações verdadeiras de outras esferas virtuais que não representam a esfera real percebida foi previamente discutida em termos de fazer performances e declarações verdadeiras sobre os chamados personagens fictícios (COLAPIETRO, 2009, p. 117; SEARLE, 1975, p. 329).

Nossa discussão anterior sobre objetos indiciais também atesta que uma esfera virtual pode ser verdadeira para objetos que são materiais ou mentais. Esta é uma observação crucial e, de certo modo, autoevidente, mas muitas vezes negligenciada. De acordo com o meu ponto de vista, um conceito de veracidade que inclua apenas conexões reais com estados materialmente observáveis é talvez mais fácil de gerenciar, mas de pouca utilidade. 
Conectando a uma antiga distinção de Aristóteles, podemos, além disso, dizer que uma esfera virtual pode ser verdadeira para objetos que são (mais ou menos) universais ou aqueles que são específicos (ARISTOTLE, 1997 [330 BCE], p. 81; GALE, 1971, p. 335; GALLAGHER, 2006, p. 341-343; WALTON, 1983, p. 80). Algumas variações dessa distinção seriam dizer que uma esfera virtual pode ser verdadeira para objetos típicos ou atípicos; permanentes ou temporários; e global ou local. Isso poderia, talvez, ser entendido como um tipo de visão estatística sobre a veracidade, relacionada com a probabilidade da existência de repetidas contiguidades em vários ambientes e circunstâncias; veracidade em função de certas maneiras de enquadrar o domínio extracomunicacional.

De uma maneira relacionada, uma esfera virtual pode ser verdadeira para objetos que são completos ou para objetos que são detalhes (PAVEL, 1986, p. 17). $A$ veracidade nos detalhes não garante um todo verdadeiro e um todo verdadeiro pode abrigar detalhes não verdadeiros. Esta é a veracidade entendida como percepção dos gestalts; veracidade que emana da (des)atenção para (ausência de) conexões reais singulares ao interpretar o padrão geral de contiguidade.

Uma importante, porém mais complexa maneira de classificar os objetos indiciais extracomunicacionais, coincidindo em parte com algumas das categorias anteriores, é que uma esfera virtual pode ser verdadeira para objetos que anteriormente foram manifestados, que são atualmente manifestados, que estão destinados a se manifestar ou que podem se manifestar ${ }^{6}$. Pode-se até argumentar que uma esfera virtual pode ser verdadeira para objetos que deveriam ser manifestados. Essas últimas formas de veracidade dependem fortemente da contiguidade mental.

Neste contexto, deve também ser notado que qualquer item material pode ser atraído para o ato comunicativo e se tornar um produto de mídia que interage com outros produtos de mídia ou cria produtos de mídia convergentes, altamente multimodais. Nos tribunais, por exemplo, impressões digitais e outras evidências são enquadradas de tal forma que elas se comunicam com mídias padrão como fala, texto escrito, imagens estáticas, filmes e gravações sonoras que as incorporam para criar uma esfera virtual baseada em forte contiguidade para a esfera real percebida. Assim, todas as variedades de contiguidade, todos os tipos de junções indiciais intracomunicacionais, e todos os tipos de objetos indiciais extracomunicacionais pertencem à veracidade externa na comunicação. Essa abundância demonstra a complexidade de formar esferas virtuais coerentes

6 Cf. a noção de "mundos possíveis", em Pavel (1986, p. 46). 
em conexão com a dimensão extracomunicacional. Há, no entanto, um fator que merece atenção especial: a mente comunicativa.

\section{Mentes comunicativas que garantem a coerência interna e a veracidade externa}

Comunicação, como definido neste artigo, é sobre a transferência de significado entre mentes. Portanto, a noção de mente comunicativa, para o momento entendido como a mente do produtor do significado, não o receptor, é pertinente. De formas relacionadas, mas claramente diferentes, é central para conceber os domínios intracomunicacionais e extracomunicacionais. Até certo ponto, as mentes comunicativas são responsáveis tanto pela (in)coerência quanto pela (in)veracidade externa. Isso acontece por meio da representação. As mentes comunicativas são feitas presentes na mente do receptor por meio dos representamens dos produtos de mídia e podem ser objetos na própria esfera virtual, em outras esferas virtuais e na esfera real percebida.

\section{Mente comunicativa real percebida}

O ponto de partida para essa investigação é a observação clara, mas fundamental, de que as mentes comunicativas, para produzirem valor cognitivo a ser compreendido via os produtos de mídia, não desaparecem simplesmente atrás das esferas virtuais criadas nas mentes dos receptores. Em muitas situações, a mente comunicativa é decididamente representada pelo produto da mídia e, portanto, torna-se parte da esfera virtual. Em uma conversa comum, por exemplo, a palavra "Eu" é frequentemente entendida como um índice, baseado em forte contiguidade no espaço e tempo reais, para a mente comunicativa na esfera real percebida usando seu corpo e suas extensões como produtos de mídia ao proferir tal palavra.

Na medida em que tudo pode ser estabelecido, esta é uma mente comunicativa determinável que pode até mesmo estar envolvida em comunicação bidirecional. Em outras situações, a mente comunicativa pode estar muito mais distante no espaço e no tempo e, por vezes, como quando se olha para pinturas rupestres antigas, a mente do emissor não é acessível e só pode ser interpretada como uma ideia de algo que deve ter existido em algum momento. A pintura se torna um índice baseado na contiguidade fraca, consistindo na noção de que alguém deve ter produzido as configurações visuais por meio de ações da mente e da 
mão. Em qualquer caso, as mentes comunicativas são sempre, se são partes da esfera real percebida, percebidas como as mentes dos perceptores reais.

As mentes comunicativas que se originam da esfera real percebida são objetos que, em vários graus, garantem a veracidade externa. Sua existência em experiências colaterais de certas partes da esfera real percebida torna plausível que certos aspectos do valor cognitivo sejam mais ou menos verdadeiros. É claro que a representação das mentes comunicativas na esfera real percebida não é em si uma garantia de veracidade completa (por exemplo, há fatores como esquecimento, equívocos e mentiras que desconectam partes do domínio intracomunicacional do domínio extracomunicacional), mas a experiência colateral das mentes comunicativas torna possível decidir parcialmente sobre a quantidade de contiguidade que está presente. Essa é uma questão imensamente complexa que não pode ser desenvolvida ainda mais no momento; aqui só quero enfatizar que as mentes comunicativas são objetos extracomunicacionais centrais; embora seus papéis possam variar consideravelmente, eles são sempre, no mínimo, elos necessários à percepção da esfera real.

\section{Mente comunicativa virtual}

Além de representar mentes comunicativas na esfera real percebida, os produtos de mídia também podem representar aqueles que emergem da esfera virtual. Como todos os objetos intracomunicacionais, as mentes comunicativas virtuais são, em última análise, construídas por objetos extracomunicacionais, o que significa que elas podem ser semelhantes às mentes comunicativas reais, percebidas. No entanto, os que receptores dos produtos de mídia que não têm conhecimento, acesso ou interesse pelos emissores reais tendem a construir esferas virtuais que incluem as mentes virtuais comunicativas como entidades comunicativas compreensíveis. $O$ anseio por coerência interna pode, portanto, ser alcançado com a ajuda de mentes virtuais comunicativas: detalhes estranhos, conexões vagas e inconsistências aparentes podem ser conectadas por meio da representação de mentes virtuais comunicativas unindo certas ideias, propósitos e peculiaridades.

A noção de mentes comunicativas virtuais combina muito bem com o que há muito é conhecido na teoria literária como "autores implícitos" (BOOTH, 1961), embora o escopo dos comunicadores virtuais seja obviamente muito maior, incluindo todos os tipos de comunicação e não apenas um certo tipo de textos escritos. A teoria literária também sugeriu uma ampla gama de agentes mediadores internos com responsabilidades e capacidades mais restritas em comparação com o autor implícito. Esses agentes são geralmente chamados de focalizadores 
(restringindo o que é comunicado ao escopo do que certos personagens conhecem, veem ou ouvem) ou narradores, com vários prefixos (agentes responsáveis pela comunicação dentro do quadro geral da esfera virtual). Como a noção de narrador tem sido usada principalmente para os tipos de mídia, incluindo a linguagem verbal, o termo "monstrator" tem sido sugerido para denotar uma noção correspondente de tipos de mídia icônicos visuais (GAUDREAULT, 2009)7. Esses agentes são objetos intracomunicacionais que podem ser combinados de muitas e, às vezes, de maneiras complexas. Eles têm em comum a função de interconectar as partes de uma esfera virtual de modo que as esferas virtuais compostas também possam ser entendidas como totalidades.

Além disso, uma esfera virtual pode representar uma multiplicidade de agentes de outras esferas virtuais: mentes comunicativas reais, mentes virtuais comunicativas e também agentes mediadores internos, como narradores. Todos eles são objetos extracomunicacionais que podem ser incorporados em uma esfera virtual de maneiras intricadas.

\section{Veracidade na chamada ficção}

Para encerrar este artigo, colocarei a veracidade externa em relação às noções contrastantes de ficção e de ficcionalidade. A ficcionalidade é normalmente entendida como uma suposta qualidade (pelo menos parcial) de certos tipos de mídia rotulados como ficções - "novela, conto, novela gráfica, ficção, seriado televisivo e assim por diante" (SKOV NIELSEN et al., 2015, p. 62; SEARLE, 1975, p. 332) -e pertencente à representação de objetos inventados, irreais e puramente imaginários.

Em outras palavras, a ficcionalidade não é supostamente uma representação de objetos da esfera real percebida, mas apenas de objetos da esfera virtual ou de outras esferas virtuais que não representam a esfera real percebida. Essa noção encontra problemas ao considerar que todos os objetos intracomunicacionais dependem, em última instância, de objetos extracomunicacionais, embora surjam dentro do domínio intracomunicacional e possam ganhar uma espécie de autonomia ao serem percebidos como novos gestalts. Uma conclusão mínima dessa observação é que a ficcionalidade é muito difícil de ficar circunscrita por causa das fronteiras flutuantes entre objetos extracomunicacionais e novas gestalts intracomunicacionais.

Publicado originalmente em 1988. 
Uma conclusão mais drástica é que não há uma qualidade específica de ficcionalidade, apenas tipos e graus de veracidade. A ficcionalidade, se é que a noção deve ser mantida, não deve, portanto, ser entendida como uma característica distinta, mas como uma falta de certos tipos de veracidade. Com efeito, isso torna a noção de ficcionalidade supérflua e a oposição como veracidade - ficcionalidade enganosa. Defendo, portanto, que a veracidade e a chamada ficcionalidade não são duas qualidades contrárias; em vez disso, elas representam diferentes graus na mesma escala. Abandonar a noção de ficcionalidade livra-nos de lastro pesado, mas vazio, e nos deixa com uma noção homogênea, mas de fato muito complexa, de tipos e graus de veracidade.

Se a noção de ficcionalidade é abandonada, o que resta então da ficção, supostamente baseada na ficcionalidade? Em todas as circunstâncias, é claro que não se pode fazer "uma distinção categórica" entre ficção e não ficção (YADAV, 2010, p. 191; RYAN, 1991). A não ficção, se a noção for mantida no discurso acadêmico, deve ser entendida como uma variedade de tipos de mídia que se espera que tenham certos tipos de veracidade. Ficção, uma noção igualmente problemática, seria então uma gama de tipos de mídia dos quais se espera faltem certos tipos de veracidade. No entanto, isso não elimina a condição de haver veracidade tanto na ficção (incluindo tipos de mídia como romances, desenhos animados e baladas) quanto na não ficção (como documentários, artigos científicos e testemunhos orais). Isso tem sido reconhecido de várias maneiras por vários estudiosos que diferem em suas concepções e terminologias (por exemplo, D'ALESSANDRO, 2016; GALE, 1971; GRISHAKOVA, 2008; HARSHAW, 1984; RONEN, 1988; RYAN, 1980; SEARLE, 1975).

Como eu entendo que essa concepção de ficção versus não ficção é muito grosseira e desnecessariamente problemática, penso que haveria uma melhor compreensão das variedades de veracidade na comunicação se cada tipo de mídia fosse investigado em uma escala mais refinada em relação à veracidade esperada em termos de diferentes tipos de contiguidade e diferentes tipos de objetos indiciais extracomunicacionais. Deixe-me ilustrar isso com algumas observações de alguns tipos de mídia da perspectiva histórica e cultural em que esse autor está situado.

Espera-se que os noticiários televisivos sejam fortemente verdadeiros de várias maneiras. Eles devem preferencialmente incluir fotografias ou filmagens produzidas por contiguidade eletromagnética ou química. Eles certamente devem ser verdadeiros para os objetos na esfera real percebida, mas também para os objetos em outras esferas virtuais, o que significa que a comunicação anterior deve ser relatada corretamente. Os programas também devem ter co- 
nexões reais com objetos materiais e mentais; não apenas para pessoas, lugares e eventos, mas também para objetos como ideias e emoções. Tanto o todo como os detalhes devem aparecer corretamente. É importante ressaltar que se espera que esses programas representem verdadeiramente objetos que são particulares, independentemente de seu grau de universalidade, o que significa também objetos atípicos e temporários, em vez de permanentes, fazem parte de sua norma. Além disso, eles devem ser igualmente verdadeiros para objetos que foram manifestados e aqueles que são manifestados no momento - e, se possível, para objetos que podem ou devem se manifestar.

Em contraste, espera-se que as pinturas históricas sejam fortemente verdadeiras em alguns aspectos e menos verdadeiras em outros. Para fazer parte deste tipo de mídia, um produto deve ser produzido por contiguidade mental e mecânica por uma pessoa que possua experiência colateral relevante. Uma pintura histórica deve ser verdadeira para objetos visuais, principalmente materiais. Embora a qualidade da universalidade seja certamente possível de incluir, espera-se, antes de tudo, ter conexões reais com objetos específicos de um determinado tempo e lugar. Prevê-se que seja verdadeiro tanto para o todo como para os detalhes, embora os detalhes mais pequenos sejam frequentemente descontados. Enquanto a norma primária é representar de forma verdadeira os objetos que foram manifestados, isso pode ser combinado com uma representação verdadeira dos objetos que podem se manifestar de acordo com a ideia de que a história pode se repetir.

Um terceiro exemplo são os romances de ficção científica que se espera sejam mais ou menos verdadeiros ainda que de outras maneiras quando comparados a reportagens e pinturas históricas. Em certa medida, eles deveriam ser verdadeiros para objetos em outras esferas virtuais, o que significa que os seus próprios objetos devem, de preferência, corresponder a outras ficções científicas para fazer sentido. A maioria dos leitores provavelmente antecipa que eles representam mais ou menos objetos universais; que sejam histórias que dizem muito sobre as coisas em geral e de maneira global. Claro, isso não exclui representações verdadeiras de objetos atípicos e espetaculares. Naturalmente, os romances de ficção científica devem, em primeiro lugar, ser verdadeiros para objetos que podem ser, e talvez até certo ponto, podem ou não, ser manifestados no futuro.

Minha afirmação aqui não é que as expectativas esboçadas de um punhado de tipos de mídia sejam precisas, mas sim que existem várias antecipações mutáveis desses tipos que são importantes para a interpretação dos tipos de mídia. Isso quer dizer que tipos diferentes de mídia e submídia, ou gêneros, são frequentemente qualificados exatamente em relação à presença ou ausência 
esperada de vários tipos de veracidade extracomunicacional (ELLESTRÖM, 2010); tipos de mídia são parcialmente definidos pelos próprios tipos de veracidade nos produtos de mídia que os constituem (WILDEKAMP et al., 1980, p. 556). Atribuições do tipo de mídia como "esta é uma conversa de jantar, mas isso é um testemunho legal" podem ser entendidas como reivindicações de verdade. Além disso, as variedades esperadas ou mesmo necessárias de veracidade e não veracidade são frequentemente consideradas como andando de mãos dadas com certos estilos e outras características da mídia. No final, no entanto, os tipos de mídia qualificados certamente não são entidades estáveis, mas importantes categorias pragmáticas que variam com a história, as ideologias e as culturas. 0 mapeamento de tantas e múltiplas diversidades é necessário para transcender a tão grosseira distinção entre ficção e não ficção.

\section{Considerações finais}

Elaborei uma nova abordagem para algumas questões fundamentais de comunicação, efetuadas de uma forma que inclui todos os tipos concebíveis de mídia. O modelo resultante sugere que o resultado da comunicação é, minimamente, uma esfera virtual na mente do receptor. Essa esfera virtual é constituída por objetos (entendidos em um sentido semiótico) que emanam da esfera real percebida e de outras esferas virtuais, mas também por objetos que emergem dentro da esfera virtual. Argumentei, no entanto, que tais objetos intracomunicacionais são, em última instância, derivados de objetos extracomunicacionais originários de outras esferas virtuais e da esfera real percebida.

Com base nessa concepção, afirmei que há duas funções principais de índices na comunicação. Índices baseados em contiguidade ou conexões reais, por um lado, geram coerência interna na esfera virtual; por outro lado, criam veracidade externa ao ligar os domínios intracomunicacionais e extracomunicacionais. Em contraste com outros tipos de signos, que podem de fato corresponder corretamente à extracomunicação, os índices são aqueles signos que realmente criam a veracidade.

Como existem muitas subclasses de contiguidade, a coerência interna pode ser criada de várias maneiras. No entanto, a noção de coerência interna em uma esfera virtual é vital para o desenvolvimento da noção de narração, que foi apenas sugerida aqui. Mais esforços têm sido feitos para demonstrar não apenas que existem muitas variedades de contiguidade, mas também que esferas virtuais podem ser verdadeiras para uma ampla diversidade de objetos extracomunicacionais. A observação simultânea desses dois fatores multifacetados tornou 
possível sugerir os contornos de uma concepção imensamente diferenciada de graus e variedades (ausentes) de veracidade externa. Tal concepção, sustentei, torna a noção de ficcionalidade supérflua, pois é simplesmente equivalente a uma falta de certos tipos de veracidade.

Eu também sustentei a opinião de que as afirmações de verdade podem ser atribuições de tipos de mídia. Uma das muitas funções de categorização da mídia é indicar que tipos de veracidade externa podem ser esperados de certos produtos. No entanto, classificações grosseiras como ficção versus não ficção distorcem a percepção refinada das nuances na veracidade externa.

\section{Referências}

ARISTOTLE. [c. 330 BCE]. In: BAXTER, John; ATHERTON, Patrick (ed.). Aristotle's Poetics. Tradução de George Whalley. Montreal: McGill-Queen's University Press, 1997.

ATKIN, Albert. Peirce on the index and indexical reference. Transactions of the Charles S. Peirce Society, Bloomington, v. 41, n. 1, p. 161-188, 2005.

BAXTER, John; ATHERTON, Patrick (ed.). Aristotle's poetics. Tradução de George Whalley. Montreal: McGill-Queen's University Press, 1997.

BERGMAN, Mats. Experience, purpose, and the value of vagueness: On C. S. Peirce's contribution to the philosophy of communication. Communication Theory, Malden, v. 19, 2009. p. 248-277. https://doi.org/10.1111/j.1468-2885.2009.01343.x

BOOTH, Wayne C. The rhetoric of fiction. Chicago: University of Chicago Press, 1961.

BREWER, William F. Schemas versus mental models in human memory. In: MORRIS, Peter (ed.). Modelling cognition. Oxford: Oxford University Press, 1987. p. 187-197.

BURKE, Tom. Peirce on truth and partiality. In: BARWISE, Jon; MARK GAWRON, Jean; PLOTKIN, Gordon; TUTIYA, Syun (ed.). Situation theory and its applications. Stanford: Center for the Study of Language and Information, 1991. p. 115-146. v. 2. https://doi. org/10.2307/416243

BURKS, Arthur (ed.). The collected papers of Charles Sanders Peirce. Cambridge MA: Harvard University Press, 1958. v. 8.

COLAPIETRO, Vincent. Pointing things out: Exploring the indexical dimensions of literary texts. In: VEIVO, Harri; LJUNGBERG, Christina; JOHANSEN, Jørgen Dines (ed.). Redefining literary semiotics. Newcastle upon Tyne: Cambridge Scholars Press, 2009. p. 109-133.

D'ALESSANDRO, William. Explicitism about truth in fiction. British Journal of Aesthetics, London, v. 56, p. 53-65, 2016. 
ELLESTRÖM, Lars. The modalities of media: A model for understanding intermedial relations. In: ELLESTRÖM, Lars (ed.). Media borders, multimodality and intermediality, Basingstoke: Palgrave Macmillan, 2010. p. 11-48. https://doi.org/10.1057/9780230275201 2

ELLESTRÖM, Lars. Material and mental representation: Peirce adapted to the study of media and arts. American Journal of Semiotics, Bloomington, v. 30, n. 1/2, p. 83-138, 2014. https://doi.org/10.5840/ajs2014301/24

ELLESTRÖM, Lars. A medium-centered model of communication. Journal of the International Association for Semiotic Studies, Basingstoke, n. 224, 2018.

GALE, Richard M. The fictive use of language. Philosophy, Cambridge, v. 46, n. 178, p. 324-340, 1971. https://doi.org/10.1017/s003181910001696x

GALLAGHER, Catherine. The rise of fictionality. In: MORETTI, Franco (ed.). The novel. Princeton: Princeton University Press, 2006. p. 336-363. v. 1, History, geography and culture.

GAUDREAULT, André. From Plato to Lumière: Narration and monstration in literature and cinema. Tradução de Timothy Barnard. Toronto: University of Toronto Press, 2009. https://doi.org/10.3138/9781442688148

GODOY, Hélio. Documentary realism, sampling theory and Peircean semiotics: Electronic audiovisual signs (analog or digital) as indexes of reality. Doc On-line, [S. l.], n. 2. p. 107-117, jul. 2007.

GOUDGE, Thomas A. Peirce's index. Transactions of the Charles S. Peirce Society, Bloomington, v. 1, n. 2, p. 52-70, 1965.

GRISHAKOVA, Marina. Literariness, fictionality, and the theory of possible worlds. In: SKALIN, Lars-Åke (ed.). Narrativity, fictionality, and literariness: The narrative turn and the study of literary fiction. Örebro: Örebro University Press, 2008. p. 57-76.

HARSHAW, Benjamin. Fictionality and fields of reference: Remarks on a theoretical framework. Poetics Today, Tel Aviv, v. 5. n. 2, p. 227-251, 1984. https://doi. org/10.2307/1771931

HOOKWAY, Christopher. Truth, rationality, and pragmatism: Themes from Peirce. Oxford: Clarendon Press, 2000.

HOWAT, Andrew W. Hookway's Peirce on assertion \& truth. Transactions of the Charles S. Peirce Society, Bloomington, v. 51, n. 4, p. 419-443, 2015. https://doi.org/10.2979/ trancharpeirsoc.51.4.03

MCCARTHY, Jeremiah. Semiotic idealism. Transactions of the Charles S. Peirce Society, Bloomington, v. 20, n. 4, p. 395-433, 1984. 
NESHER, Dan. Peircean realism: Truth as the meaning of cognitive signs representing external reality. Transactions of the Charles S. Peirce Society, Bloomington, v. 33, n. 1, p. 201-257, 1997.

PAVEL, Thomas G. Fictional Worlds. Cambridge MASS: Harvard University Press, 1986. PEIRCE, Charles Sanders. Drafts of a review of Josiah Royce's The World and the Individual. In: BURKS, Arthur (ed.). The collected papers of Charles Sanders Peirce. Cambridge MA: Harvard University Press, 1958. cap. 4. https://doi.org/10.2307/2270842

PEIRCE, Charles Sanders. Fragment on consciousness and reasoning. In: BURKS, Arthur (ed.). The collected papers of Charles Sanders Peirce. Cambridge MA: Harvard University Press, 1958. cap. 7. https://doi.org/10.2307/2270842

PEIRCE, Charles Sanders. Index. In: BALDWIN, James Mark (ed.). Dictionary of philosophy and psychology. New York: Macmillan, 1901. v. 1.

PEIRCE, Charles Sanders. One, two, three: fundamental categories of thought and of nature. In: BURKS, Arthur (ed.). The collected papers of Charles Sanders Peirce. Cambridge MA: Harvard University Press, 1958. p. 369-378. https://doi.org/10.2307/2270842

PEIRCE, Charles Sanders. Prolegomena to an apology for pragmaticism. In: BURKS, Arthur (ed.). The collected papers of Charles Sanders Peirce. Cambridge MA: Harvard University Press, 1958. cap. 4. https://doi.org/10.2307/2270842

PEIRCE, Charles Sanders. The art of reasoning. In: BURKS, Arthur (ed.). The collected papers of Charles Sanders Peirce. Cambridge MA: Harvard University Press, 1958. v. 2. https://doi.org/10.2307/2270842

PEIRCE, Charles Sanders. Letter draft. In: BURKS, Arthur (ed.). The collected papers of Charles Sanders Peirce. Cambridge MA: Harvard University Press, 1958. cap. 8. https:// doi.org/10.2307/2270842

PEIRCE, Charles Sanders. Notes on topical geometry. In: The collected papers of Charles Sanders Peirce. Cambridge MA: Harvard University Press, 1958. cap. 8. https://doi. org/10.2307/2270913

RONEN, Ruth. Completing the incompleteness of fictional entities. Poetics Today, Tel Aviv, v. 9, p. 497-514, 1988. https://doi.org/10.2307/1772729

RYAN, Marie-Laure. Fiction, non-factuals, and the principle of minimal departure. Poetics, North Holland, v. 9, n. 4, p. 403-422, 1980. https://doi.org/10.1016/0304-422x(80)90030-3

RYAN, Marie-Laure. Fiction as a logical, ontological, and illocutionary issue. Style, Pennsylvania, v. 18. n. 2, p. 121-139, 1984.

RYAN, Marie-Laure. Possible worlds, artificial intelligence, and narrative theory. Bloomington: Indiana University Press, 1991. 
SEARLE, John R. The logical status of fictional discourse. New Literary History, [S. l.], v. 6, n. 2, p. 319-332, 1975. https://doi.org/10.2307/468422

SKOV NIELSEN, Henrik; PHELAN, James; WALSH, Richard. Ten theses about fictionality. Narrative, v. 23, n. 1, p. 61-73, 2015. https://doi.org/10.1353/nar.2015.0005

STJERNFELT, Frederik. Natural propositions: the actuality of Peirce's doctrine of dicisigns. Boston MA: Docent Press, 2014.

WALTON, Kendall L. Fiction, fiction-making and styles of fictionality. Philosophy and Literature, Baltimore, v. 7, n. 1, p. 78-88, 1983. https://doi.org/10.1353/phl.1983.0004

WEST, Donna E. Indexical reference to absent objects. Chinese Semiotic Studies, Berlin, v. 6, n. 1, p. 280-294, 2009.

WEST, Donna E. Cognitive and linguistic underpinnings of deixis am phantasma: Bühler's and Peirce's semiotic. Sign Systems Studies, v. 41, n. 1, p. 21-41, 2013. https:// doi.org/10.12697/sss.2013.41.1.02

WILDEKAMP, Ada, VAN MONTFOORT, Ineke; VAN RUISWIJK, Willem. Fictionality and convention. Poetics, North Holland, v. 9, p. 547-567, 1980. https://doi.org/10.1016/ 0304-422x(80)90006-6

YADAV, Alok. Literature, fictiveness, and postcolonial criticism. Novel, [S. l.], v. 43, n. 1, p. 189-196, 2010. https://doi.org/10.1215/00295132-2009-081

\section{Dados do autor:}

Lars Elleström é professor de Literatura Comparada na Universidade de Linnæus, Suécia, e preside o Conselho da Sociedade Internacional de Estudos Intermediários. Escreveu e editou vários livros, incluindo Divine Madness (2002), Media Borders, Multimodality and Intermediality (2010), Media Transformation (2014) e Transmedial Narration (2019). Também publicou vários artigos sobre intermedialidade, multimodalidade, semiótica, poesia, gênero, ironia e comunicação.

\section{Endereço do autor:}

Linnaeus University - Department of Film and Literature, 35195 Växjö - Sweden 